\title{
Internet Marketing Strategi Untuk Meningkatkan Pemasaran Industri Kopiah Desa Temboro Karas Magetan
}

\author{
Rizal Ula Ananta Fauzi*1, Dian Citaningtyas Ari Kadi², Wisnu Waluyo ${ }^{3}$, Muhammad Adib Zakaria4, \\ Endang Lestari ${ }^{5}$, Nadyla Octavia ${ }^{6}$, Novi Tri Laksono ${ }^{7}$ \\ 1,2,3,4,5,6,7Program Studi Manajemen Universitas PGRI Madiun, Indonesia \\ *e-mail: rizalmanajemen@gmail.com ${ }^{1}$
}

\begin{abstract}
Abstrak
Pengabdian Masyarakat merupakan implementasi dari Tridarma perguruan tinggi untuk membantu masyarakat. Pengabdian Masyarakat ini untuk menemukan permasalahan yang dihadapi Iindustri Kopiah Desa Temboro. Indutri Kopiah tersebut dalam hal pemasaran masih kurang evektif, pasalnya mereka hanya memasarkan di lingkungan sekitar kampung tersebut yang notabennya memang sudah banyak masyarakat Temboro kesehariannya menggunakan kopiah. Maka dari itu tujuan Abdi Masyarakat kami ini akan mengenalkan cara pemasaran yang lebih meluas dan tentunya juga hemat biaya yaitu dengan cara penjualan dengan basis media online, Publikasi pada media sosial,dan meelalui media Ecommerce. kegiatan pengabdian dibantu oleh para mahasiswa sekaligus sebagai pembelajaran kewirausahaan bagi mahasiswa sebagai pengetahuan berwirausaha. Inovasi yang dilakukan adalah melakukan pengembangan pemasaran melalui media berbasis E-commerce yang bertujuan untuk memperluas segmen pasar dari industri kopiah tersebut. Dari hasil pengabdian diperoleh situs web dan telegram yang dijadikan alamat untuk pemasaran online kopyah temboro sehingga memperluas pangsa pasar usaha Kopyah temboro dimasa new normal.
\end{abstract}

Kata kunci: internet pemasaran, kopyah, strategi.

\begin{abstract}
Community Service is an implementation of the Tridarma of higher education to help the community. This Community Service is to find the problems faced by the Temboro Village Coffeeah Industry. The Kopiah industry in terms of marketing is still not very effective, the reason is that they only market in the neighborhood around the village which, in fact, many Temboro people use their skullcap daily. Therefore, the aim of our Community Servant is to introduce a more widespread and of course also cost-effective way of marketing, namely by selling on the basis of online media, publication on social media, and through Ecommerce media. Community service activities are assisted by students as well as entrepreneurship learning for students as entrepreneurial knowledge. The innovation carried out is to develop marketing through $E$ commerce-based media which aims to expand the market segment of the skullcap industry. From the results of this dedication, a website and telegram were obtained which were used as addresses for online marketing of Kopyah Temboro so as to expand the market share of Kopyah Temboro businesses in the new normal era.
\end{abstract}

Keywords: internet marketing, kopyah, strategy.

\section{PENDAHULUAN}

Desa Temboro dengan luas 517.320 Ha yang terletak terletak di kecamatan Karas kabupaten Magetan Jawa Timur. Terdapat Pondok Pesantren Al-Fatah di Desa ini. Religiusnya suasana Pondok membuat masyarakat Desa Temboro terbiasa memakai busana muslim. Kaum wanita memakai pakaian tertutup sesuai syariat agama. Kaum laki - laki banyak yang memakai gamis dan kopiah untuk aktifitas sehari-hari. Tidak heran ketika terdengar suara adzan seluruh penduduk akan memadati Masjid-Masjid sekitar Desa.

Kehadiran Pondok Pesantren Al-Fatah Di Desa Temboro tidak hanya membuat pendidikannya yang terus berkembang namun perekonomiannya terus berkembang seiring dengan perjalanan waktu. Terutama saat tahun ajaran baru dan pertemuan orang tua santri. Pada saat momen seperti itu banyak sekali pedagang meraih omset penjualan tinggi. Salah satunya penjualan kopiah buatan Bpk. M. Abdul Gony.

Dari hasil kunjungan ke tempat industri kopiah Temboro bapak M. Abdul Gony ada beberapa permasalahan yang dihadapi yaitu terletak pada pemasaran. Pada aspek pemasaran indutri kopiah Temboro hanya mengandalkan pemasaran secara tradisional, yaitu dari toko ke 
toko dan mulut ke mulut. Sehingga jangkauan konsumen masih relatif sedikit. strategi pemasaran belum memanfaatkan internet marketing, dikarenakan belum adanya informasi cara memanfaatkan internet sebagai strategi pemasaran. Perlu adanyan pemsaran online untuk memperluas pasar dari produksi kopyah temboro. Hal ini sesuai paper [1] dalam pemasaran online mempunyai banyak keuntungaan Diantaranya murahnya biaya dalam pemasaran dan transaksi jual beli. yang mana modal masih menjadi kendala bagi wirausaha dalam menjalankan usahanya[2]. Melihat perkembangan digitalisasi yang semakain semarak dan memasuki berbagai kalangan masyarakat. Inovasi sebagai solusi permasalahan tersebut perlu diterapkan internet marketing sebagai strategi pemasaran. Inovasi mampu memberikan nilai positif bagi pelaku UMKM, terutama dimasa new normal dengan melihat menurunnya minat konsumen maka dibutuhkan inovasi baru untuk meningkatkan ketertarikan konsumen dan mencari pangsa pasar baru. [3] dengan inovasi mampu meninggkatkan nilai value suatu barang[4].

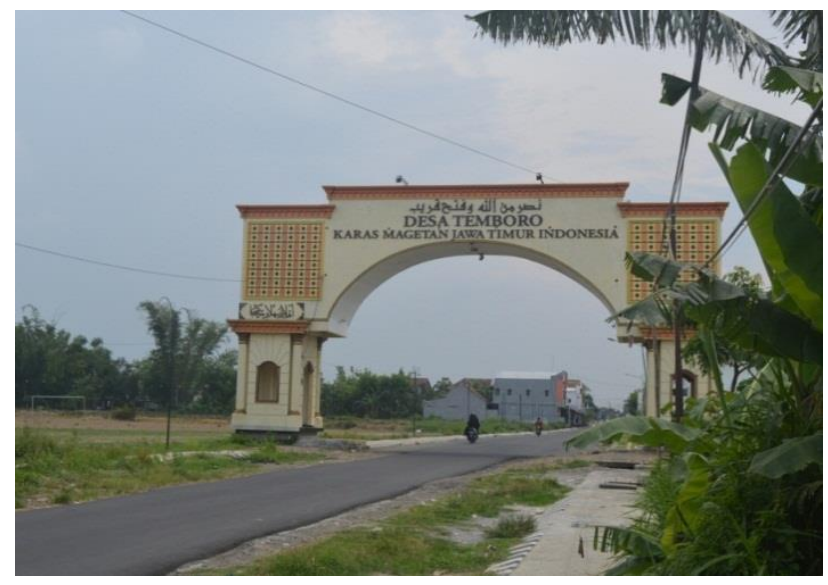

Gambar 1. Gapura masuk Desa Temboro

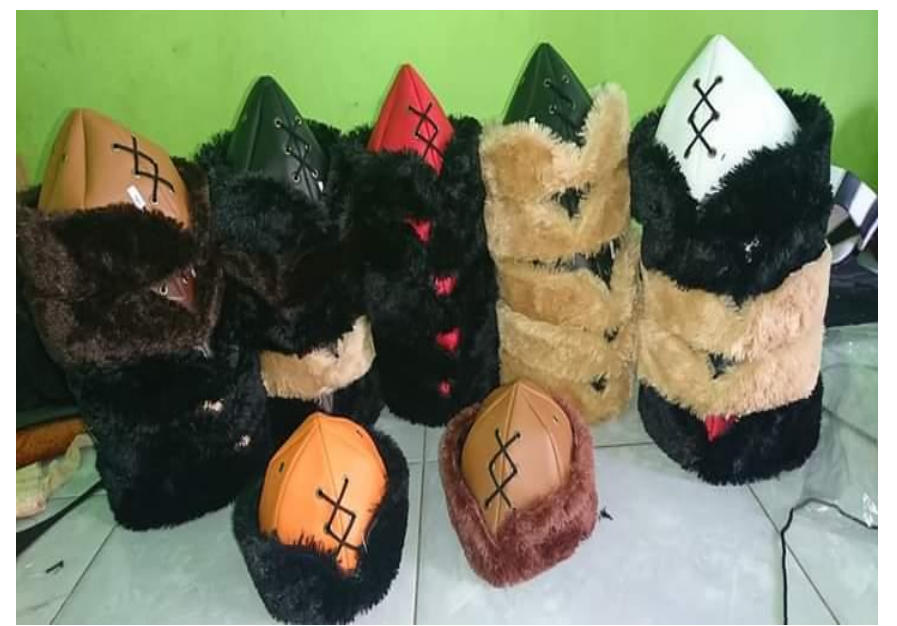

Gambar 2. Salah satu kopiah buatan Bpk M. Abdul Gony

Internet marketing yaitu usaha perusahaan dalam menjalin hubungan dengan konsumen melalui media internet untuk mepromosikan barang dan jasanya. Dalam peper [5] Digital Marketing merupakan suatu proses perencanaan dan pelaksanaan dari konsep, ide, harga, promosi dan distribusi. Media yang digunakan merupakan situs umum yang jaringan komputernya sangat besar dengan tipe berbeda di seluruh Dunia yang terhubung dalam satu wadah. Strategi internet marketing yang dibangun sebagai strategi pemasaran industri kopiah Temboro yaitu website pemasaran E-commerce dan memanfaatkan sosial media yang berbasis bisnis[6]. Dengan adanya E commerce mamapu meningkat Ewom bagi masyrakat. meningkatkan $E$-WOM yang mana $E$-WOM mampu menyebarkan informasi melalui media online atau Internet, 
seperti email, blog, ruang obrolan, Facebook, Twitter dan berbagai jenis jejaring sosial lainnya[7]

\section{Kajian Pustaka \\ 2.1 Pemasaran}

Pemasar merupakan proses mengidentifikasi dan memenuhi kebutuhan sosial manusia. pemasaran merupakan fungsi organisasi untuk menciptakan, menginformasikan dan menyampaikan nilai suatu barang kepada konsumen dan mengelolanya dengan cara hubungan yang menguntungkan dengan pelanggan dan organisasi [8]. pemasaran adalah proses managerial dan sosial untuk membuat kelompok dan individu memperoleh kebutuhan yang diinginkan melalui penciptaan, pertukaran atau timbal balik nilai produk dengan orang lain [9]. Pemasaran berorientasi pada bagaimana pemilik bisnis atau perusahaan memenuhi kebutuhan dan kepuasan pelanggan[10].

\subsection{E-commerce}

Tingginya minat masyarakat terhadap akses internet yang lebih cepat membuat WiFi menjadi suatu hal yang penting di kalangan masyarakat modern [11]. Bayak kegitan masyarakat yang dilakukan dengan cara online termasuk dalam transaksi perdagangan. E-Commerce menjadi salah satu pilihan bagi kalangan masyarakat dengan perkembangan teknologi dan masa pandemic saat ini. E-commerce merupakan aktivitas transaksi jual - beli antara penjual dan pembeli yang memanfaatkan teknologi informasi dan komunikasi elektronik yang terhubung dengan internet. E-commerce merupakan proses membeli dan menjual secara elektronik oleh konsumen dan perusahaan dengan perantara komputer [12]. E-commerce merupakan sebuah teknologi dinamis, aplikasi dan proses yang menghubungkan bisnis perusahaan, komunitas dan konsumen melalui transaksi elektronik[13.]

\subsection{Media Sosial Berbasis Bisnis}

Media sosial merupakan platform di era digital yang digunakan untuk media bersosialisasi melalui internet. Media sosial dulu pada awalnya berfungsi sebagai media pertemanan dan pertukaran informasi antar teman atau kerabat dekat, tapi saat ini juga sebagai media bisnis dan pemasaran online atau social media marketing[14]. Social media marketing : bentuk pemasaran langsung atau tidak langsung untuk membangun kesadaran, daya ingat, dan pengakuan untuk merek, orang, dan produk atau entitas lain dengan menggunakan alat web sosial. melihat potensi media sosial yang ngetren bagi masyarakat, hal ini sangat besar potensinya dalam mendukung UKM dan mampu menciptakan berpeluang yang menjanjikan. Pada masa mendatang potensi media sosial akan meningkat. Potensi mempercepat informasi, masukan dan testimoni dari konsumen, jangkauan semua kalangan media sosial sangat baik. Berikut alasan efektifitas media sosial [15.]:

a. Facebook: jangkauan luas dan penggunanya banyak, mudah dan semua orang hampir memiliki akun Facebook, interaksi dengan orang cepat .

b. Whatsapp: Whatsapp dan Facebook, lebih luas dan langsung pada produk, FB, WA hampir semua kontak WA dan teman di FB adalah teman.

c. Instagram: Instagram, sesuai anak muda masa kini, Banyak foto produk langsung bisa dilihat customer,mempunyai tampilan yang mudah dimengerti dan simpel bagi pengguna.

d. Website :Informasi dan konten yang disajikan sangat luas ( lokasi, produk, dll). 


\section{METODE}

Kegiatan pengabdian ini dilakukan beberapa tahap pada bulan november 2020 . Pengabdian ini dilakukan di industri kopiah Desa Temboro kecamatan Karas kabupaten Magetan. Beberapa tahapan yang dilakukan dapat dilihat pada gambar dibawah ini:

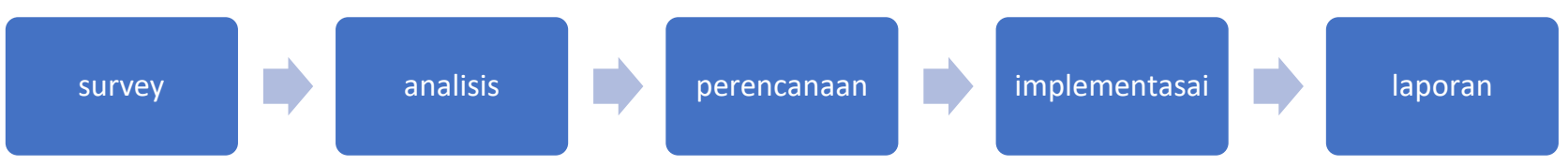

Gambar 3. Tahap Kegiatan Penganbdian

1. Tahap Survey

Tahap pertama ini melakukan survey lokasi untuk melakukan pengabdian masyarakat di Desa Temboro. Dari beberapa industri yang ditemui, pengabdian masyarakat ini kami memilih indutri kopiah.

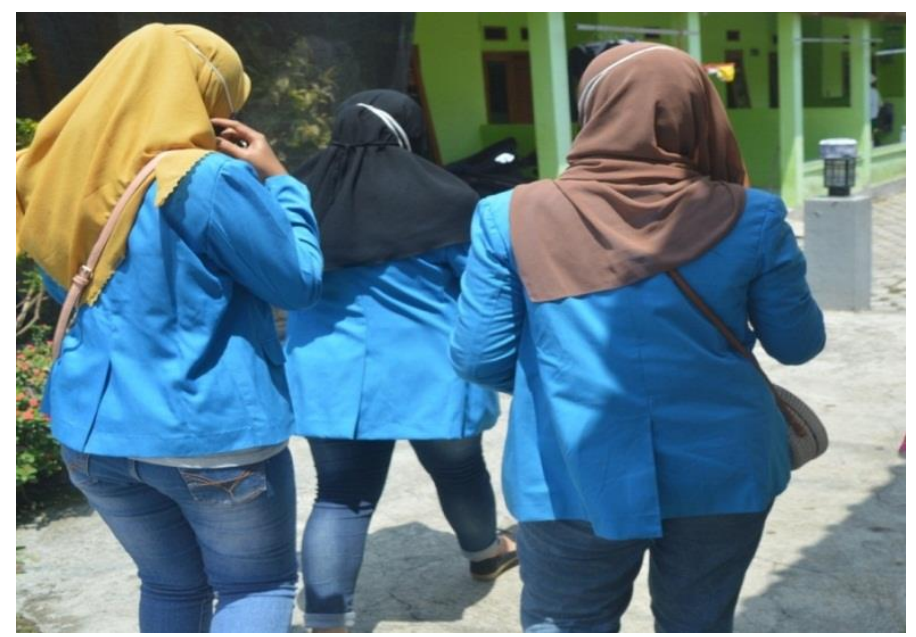

Gambar 4. Survey Lokasi

2. Tahap Analisis

Setelah menentukan industri tempat pengabdian masyarakat, kami menganalisis permasalahan yang ada di industri kopiah Temboro. Hasil analisis masalah yang dihadapi yaitu pemasaran indutri kopiah Temboro masih menggunakan pemasaran traditional yaitu memasarkan ke toko di lingkungan sekitar dan pasar dengan relatif sedikit. Indutri kopiah Temboro belum memaksimalkan teknologi internet untuk marketing. Solusi dari masalah tersebut kami membuat internet marketing dari E-commerce dan sosial media berbasis bisnis.

3. Tahap Perencanaan

Tahap ini membuat perencanaan Desain E-commerce untuk pemasaran industri kopiah Temboro. Ada beberapa Desain yang perlu dibuat sebelum diaplikasikan. Terdapat 3 Desain, diantaranya Desain halaman depan, desin halaman produk dan Desain detail produk. Untuk desain sosial media tidak memerlukan desain, sudah tersedia diaplikasi sosial media tinggal kita pilih desain yang diperlukan, hanya perlu membuat akun yang akan dibuat dan tinggal memasukan foto - foto produk dan informasi mengenai produk. 


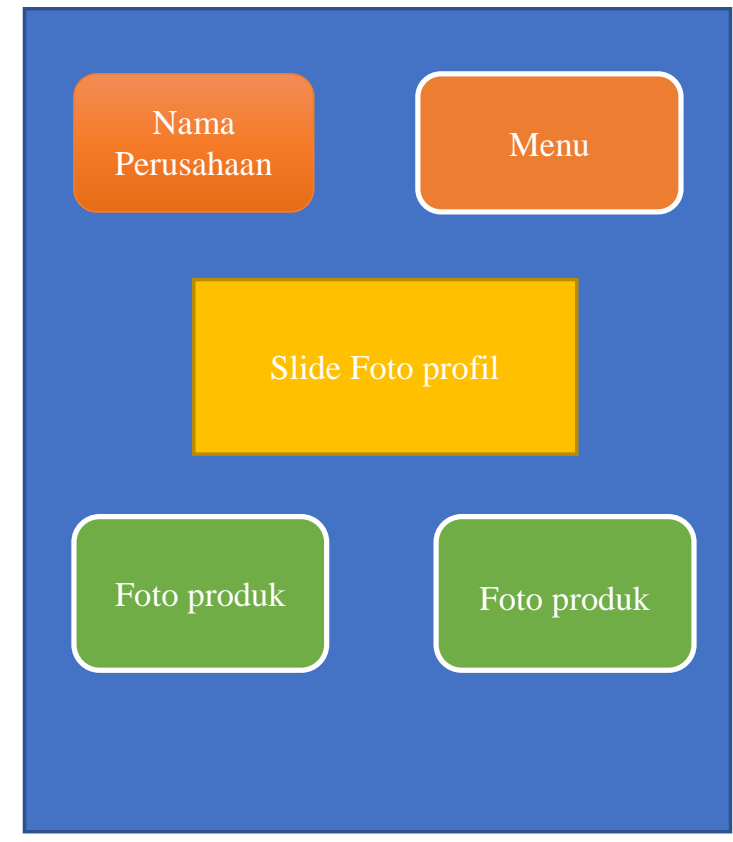

(a)

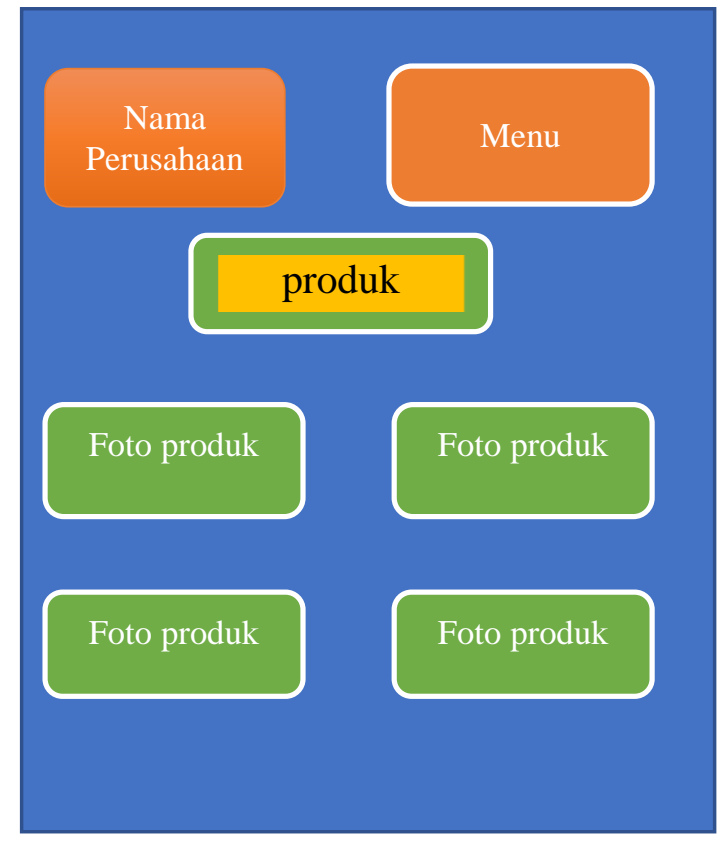

(b)

Gambar 5. Rancangan Desain web (a) gambar depan(b) gambar detail

4. Tahap Implementasi

Tahap ini pengambilan foto produk dan memngaplikasikan layout tahap sebelumnya menjadi E-commerce yang dapat digunakan. Selain itu juga membuat akun sosial media berbasis bisnis yaitu intagram.

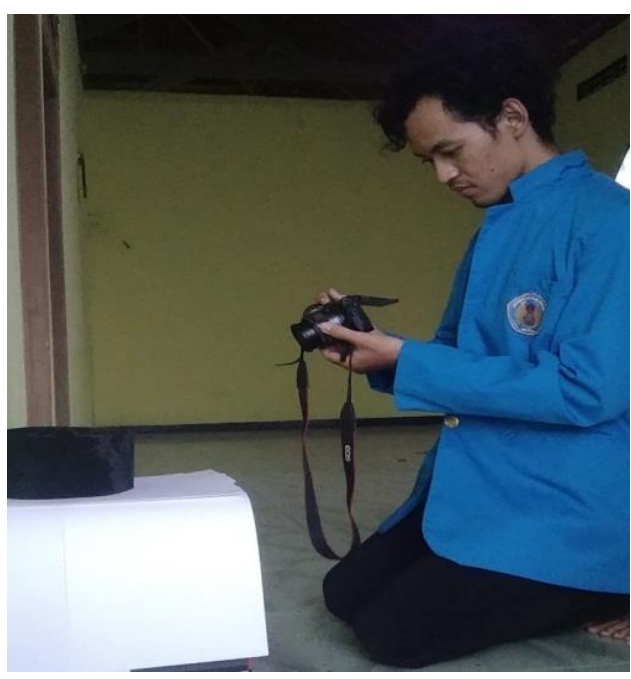

(a)

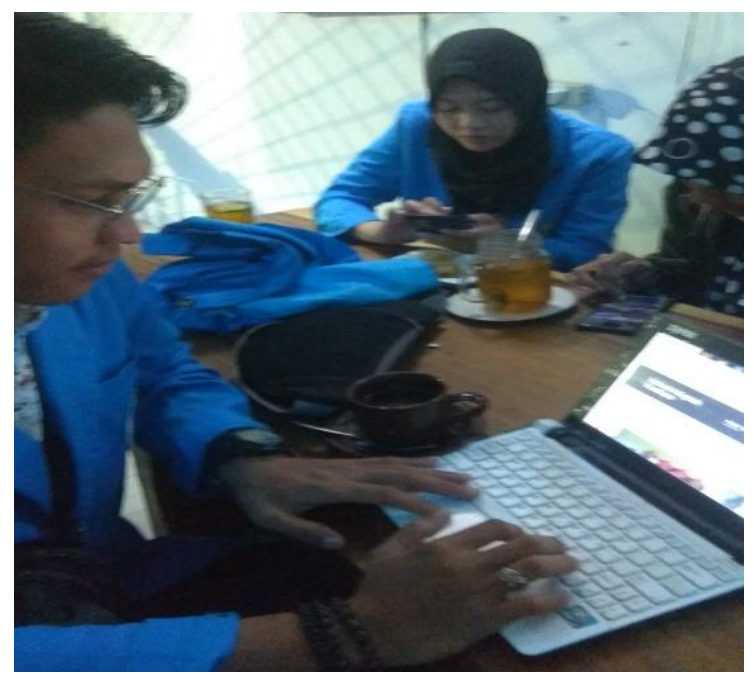

(b)

Gambar 6. Kegiatan (a) pengambilan poto produk (b) Pembuatan Website

5. Laporan

Tahap ini menguji coba web dan sosial media yang dibangun dan memastikan apakah berjalan dengan baik dan sesuai harapan. pengujian Internet marketing yang didesain sedemikian rupa agar terintregasi satu dengan lainnya. Dan hal yang tidak terpisah dari internet marketing adalah iklan/promosinya. Pengujian yang dilakukan adalah apakah Menu dan fitur E-commerce industri kopiah Temboro berjalan sesuai dengan fungsinya yang diharapkan. Berikut tabel pengujian fungsional E-commerce industri kopiah Temboro. 
Tabel 1. Daftar Pengujian

\begin{tabular}{|c|c|c|c|}
\hline Keterangan & Langkah & Harapan & Hasil \\
\hline Membuka web & \begin{tabular}{lr}
\multicolumn{2}{l}{ Mengetikkan alamat } \\
web di aplikasi \\
search \\
contoh: \\
crome
\end{tabular} & $\begin{array}{l}\text { Dapat } \\
\text { membuka/menemukan } \\
\text { alamat web }\end{array}$ & Berhasil \\
\hline Produk & $\begin{array}{l}\text { Menekan tombol } \\
\text { produk di menu bar }\end{array}$ & $\begin{array}{l}\text { Menampilkan informasi } \\
\text { macam-macam produk }\end{array}$ & Berhasil \\
\hline $\begin{array}{l}\text { Informasi produk } \\
\text { dan pemesanan }\end{array}$ & $\begin{array}{l}\text { Menekan gambar } \\
\text { produk }\end{array}$ & $\begin{array}{l}\text { Menampilkan detail } \\
\text { informasi produk dan } \\
\text { cara pemesanan }\end{array}$ & Berhasil \\
\hline Login sosial media & $\begin{array}{l}\text { Memasukkan nama } \\
\text { akun dan kode } \\
\text { masuk di aplikasi } \\
\text { instagram }\end{array}$ & $\begin{array}{l}\text { Dapat masuk ke menu } \\
\text { utama }\end{array}$ & Berhasil \\
\hline Link web & $\begin{array}{lr}\begin{array}{l}\text { Menekan } \\
\text { alamat di } \\
\text { intagram }\end{array} & \text { profil } \\
& \end{array}$ & $\begin{array}{lr}\text { Terkoneksi langsung ke } \\
\text { halaman } & \text { utama web } \\
\text { industri } & \text { kopiah } \\
\text { Temboro } & \\
\end{array}$ & Berhasil \\
\hline
\end{tabular}

\section{Hasil dan Pembahasan}

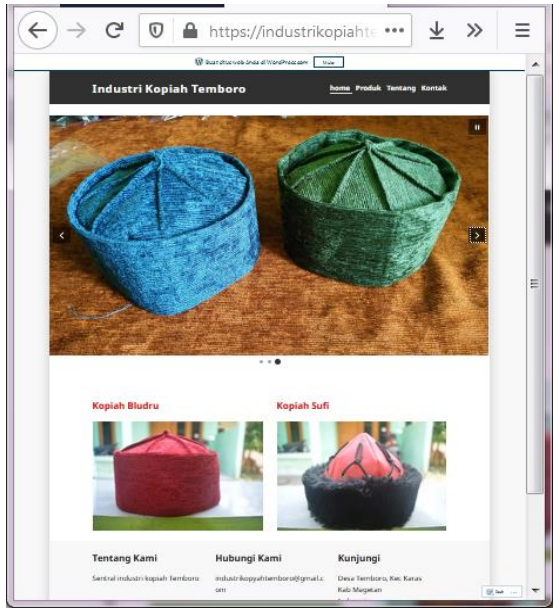

(a)

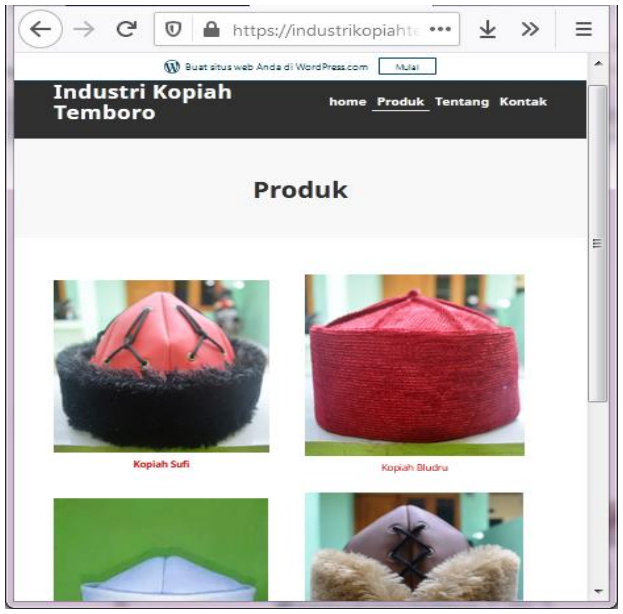

(b)

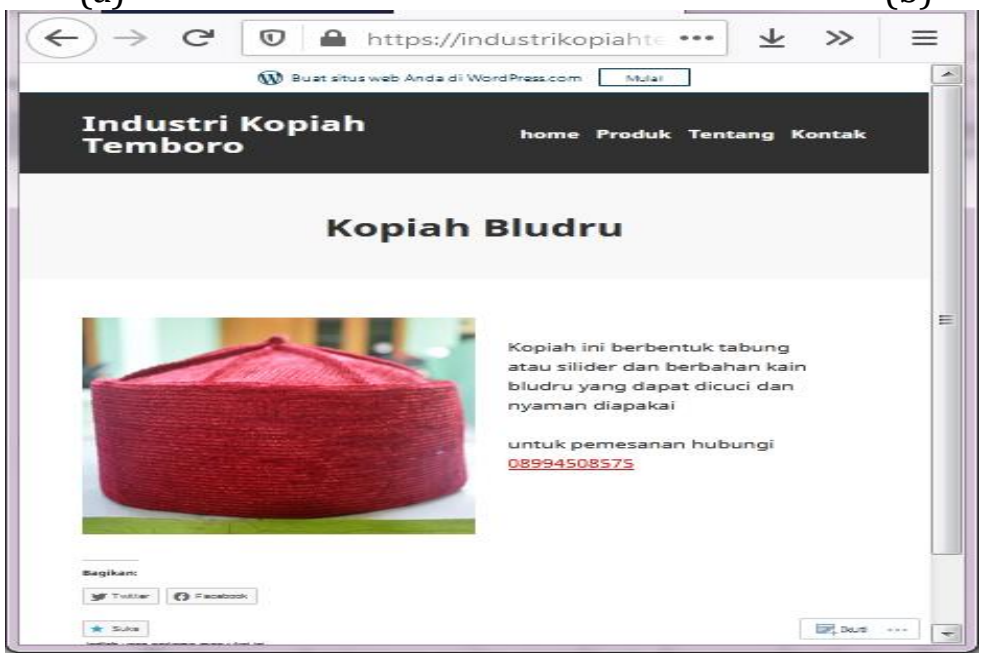

(c)

Gambar 7. Halaman web (a) halaman web(b) halaman produk (c) detail halaman 
Hasil Pengabdian ini adalah pembuatan media internet marketing, berupa website dan media sosial instragam yang saling terkoneksi sehingga memudahkan pembeli untuk memesan kopiah. Selain itu dengan adanya media ini diharapkan mampu memperluas pemasaran Industri Kopiah Temboro. Adapun kegiatan pembuatan media internet marketing yaitu mendesain Web Industri Kopiah Temboro. Untuk menciptakan ketertarikan pengunjung, maka Web perlu didesain pada halaman utama, halaman produk dan detail produk yang menarik dan informatif.

Kegiatan selanjutnya yaitu membuat dan mendesain media sosial Instagram. Banyak sekali efek-efek untuk mengedit foto di dalam Instagram agar foto yang ditampilkan menarik. Agar menarik setiap varian foto produk akan dibuat 4 frame penuh dan 1 frame untuk detail keterangan produk. Diharapkan dengan dibuatnya tampilan seperti itu agar mempermudah pembeli dan membuat kesan yang eksklusif.

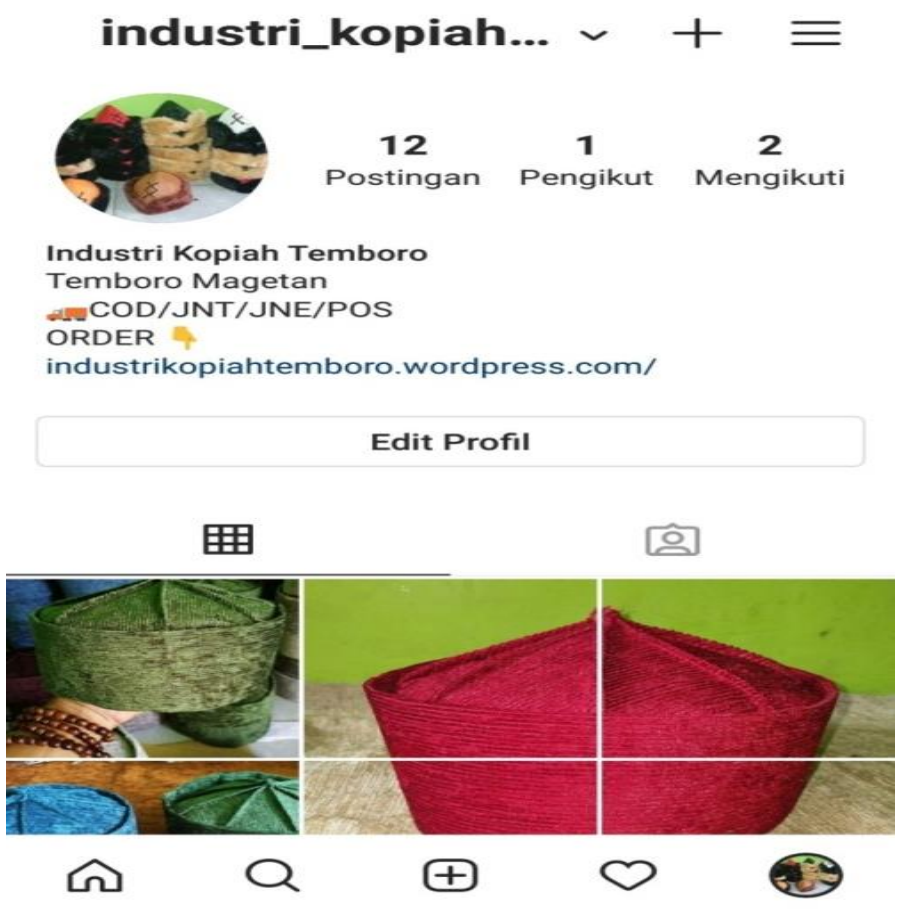

Gambar 8. Instagram industri kopiah Temboro

\section{Kesimpulan}

Permasalahan yang dihadapi industri kopiah Temboro adalah terletak pada pemasaran yang belum menggunakan internet. Peranan teknologi internet dapat menjadi alternative industri kopiah Temboro sebagai strategi pemasaran dengan media E-commerce dan sosial media bebasis bisnis.

Media web dan sosial media instagram yang diusulkan sebagai solusi alternative pemasaran yang ditawarkan ke pihak industri kopiah Temboro. Pemilihan Web dan Instagram sebagai media internet marketing dikarenakan mudah dioperasikan dan tampilannya yang menarik. Dan apabila industri kopiah Temboro terus memanfaatkan internet marketing yang sudah dibuat secara berkelanjutan, tentu akan meningkatkan penjualan dan jangkaun pemasaran produk yang lebih luas sehingga akan memperoleh profit tinggi.

\section{Daftar Pustaka}

[1] A. Hj. Arman , R. U. A. Fauzi , A. S. A. Ditta , I. Idris ,and M. F. M. Yazi," The Role of Perceived Benefits and Perceived Risks Towards the Consumers' Purchase Intention Via ECommerce: An Evidence From Indonesia," Solid State Technology, vol. 63, no. 2s, pp. 3257 - 3274, 2020.

[2] R. U. A. Fauzi ,"The Influence of Business Plan Competition and Loan Provision on Nurturing the Spirit of Entrepreneurship Among Students", Advances in Economics, 
Business and Management Research, volume 161, Proceedings of the Conference on International Issues in Business and Economics Research (CIIBER 2019) pp.188-192, 2021. https://dx.doi.org/10.2991/aebmr.k.210121.028

[3] R. U. A. Fauzi, D. C. A. Kadi, R. C. Utomo, L. Dewi, and S. R. Muhtar, " Branding dan Product Inovation Pada Usaha Mikro Kecil Menengah Krupuk Bawang Desa Mrahu Kartoharjo Magetan," Madaniya, vol. 1, no. 1, pp. 1 44-52, 2020.

[4] R. U. A. Fauzi," Marketing Strategy Analysis and Product Innovation Making added Value Bitter Melon,"Jurnal Keuangan Dan Bisnis, vol. 18, no. 1, pp. 107-115, 2020.

[5] R. U. A. Fauzi, D. C. Ari. Kadi , G. K. S. Ernanda, P. Triwidya, and S. Adhelia,"Keefektifan Peran Digital Marketing Melalui Media Sosial Dalam Proses Pemasaran Produk Galeri UMKM Ekawira, Kare Madiun," Indonesia Berdaya, vol. 2 no. 1, pp. 21 - 30, 2021.

[6] P. Kotler," Principle Of Marketing", Edisi 12. California: Pearson, 2008.

[7] D. C. A. Kadi, R. U. A. Fauzi, dan B. B. Cahyani," Strategi Pemasaran World of Mouth dan Online Dalam Sentra Industri Rumah Abon Ikan Lele di Jiwan Kabupaten Madiun,"Journal of Social Responsibility Projects by Higher Education Forum, vol. 1, no. 2, pp. 49-52, 2020.

[8] P. Kotler,"Manajemen Pemasaran “:Marketing Manajemen 9 ed. Jakarta : PT. Prenhallindo, 1996.

[9] P. Kotler, "Manajemen Pemasaran" : Analisis, Perencanaan, Implementasi, dan Kontrol. Jakarta : PT. Prenhallindo, 2001

[10] R. U. A. Fauzi,"The Role Of Free Wireless Fidelity (Wi-Fi) Service, Food Quality, And Servicescape Toward Customer Satisfaction," Asian journal of social science research, vol. 2, issue 2, 2019.

[11] R. U. A. Fauzi,"Pengaruh Harga Dan Free Wi-Fi Terhadap Keputusan Pembelian Produk Pada Angkringan Di Kecamatan Karas Kabupaten Magetan," Jurnal Aplikasi Bisnis, vol. 17 No. 2, pp. 62-74, 2017. https://doi.org/10.20885/jabis.vol17.iss2.art4

[12] K. C. Laudon and J. P. Laudon," Management Information Systems - New Approaches To Organization \& Technology". 5th edition. New Jersey : Prenticel Hall, 1998.

[13] D. Baum, "E-comemerce". Jakarta : PT Gramedia Pustaka Utama, 1999.

[14] S. Genelius," 30-Minute Social Media Marketing". United States : McGraw-Hill Companies,, 2001.

[15] S. Priambada," Potensi Media Sosial Bagi Usaha Kecil dan Menengah (UKM) di Malang Raya. Malang": Universitas Brawijaya, 2017. 